\title{
Do we experience pandemic fatigue? current state, predictors, and prevention
}

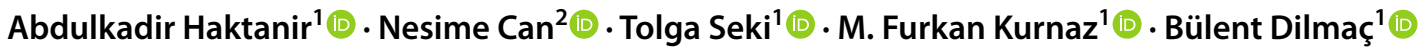

Accepted: 9 October 2021 / Published online: 20 October 2021

(c) The Author(s), under exclusive licence to Springer Science+Business Media, LLC, part of Springer Nature 2021

\begin{abstract}
There is an emerging literature on the mental and physical exhaustion due to the COVID-19 related restrictions. Some individuals seem to exercise fewer precautions recently in comparison to the onset of the pandemic in preventing the spread of the COVID-19. This phenomenon is described as pandemic fatigue. Though acknowledged in conceptual articles and news reports, there is a lack of empirical evidence pertaining to pandemic fatigue. We collected data from 516 adult participants to investigate pandemic fatigue and its relations to fear of coronavirus, intolerance of uncertainty, apathy, and self-care. 34.40\% of the participants reported that the level of COVID-19-related precautions they take have decreased in comparison to measures they took at the onset of the pandemic. Additionally, our model examining the role of fear of coronavirus, intolerance of uncertainty, and apathy as mediated by self-care predicting pandemic fatigue demonstrated acceptable to excellent goodnessof-fit indices. The fact that one in every three individuals is taking fewer precautions is not only a threat to the individuals' own health but also to the public. Given that individuals are experiencing pandemic fatigue, governments should consider paying more attention to the biopsychosocial nature of humans in ordering restrictions and planning necessary precautions.
\end{abstract}

Keywords pandemic fatigue $\cdot$ fear of COVID- $19 \cdot$ intolerance for uncertainty $\cdot$ apathy $\cdot$ self-care

The COVID-19 pandemic continues to affect increasingly more individuals across the world (WHO, 2020). As of March 15, 2021, the WHO reported approximately 120 million confirmed COVID-19 cases worldwide, with more than 2.6 million deaths (WHO, 2020). Researchers conducted studies to gain a better understanding of mental health status of various groups such as healthcare workers (Ceri \& Cicek, 2021), college students (Yalçın et al., 2021) and the general public (Emir Öksüz et al., 2021; Rossell et al., 2021). Although patients with chronic diseases and healthcare workers fighting the pandemic are stated to be the most vulnerable populations, individuals without a distinct health issue have also been affected by the pandemic. Ceri and Cicek (2021) examined the relationship between psychological well-being, depression and stress among healthcare professionals and non-healthcare professionals,

Abdulkadir Haktanir

kadirhaktanir@gmail.com

1 Psychological Counseling and Guidance, Necmettin Erbakan University, Konya, Turkey

2 Psychological Counseling and Guidance, Ankara University, Ankara, Turkey and results revealed no significant difference in scores of two groups, which may be interpreted as that both groups are affected by the pandemic similarly.

Due to COVID-19, many individuals have lost jobs, worked decreased hours, shifted to working from home, contracted the virus, or lost loved ones, which may deteriorate mental health (Arpaci et al., 2020; Witteveen \& Velthorst, 2020). Although these changes may have seemed personal, the uncertainty about how the pandemic would proceed and when it would come to an end may affect many individuals and families economically, socially, and psychologically. Therefore, it may be helpful to conceptualize the pandemic and its consequences from a broad perspective.

\section{Pandemic fatigue}

The adverse psychological effects of the pandemic are well documented. Researchers reported that individuals experience increased levels of stress, anxiety, depression, and obsessive-compulsive tendencies (Emir Öksüz et al., 2021; Tanhan, 2020), that they feel emotionally drained and unable to function efficiently (Vindegaard \& Benros, 2020), and that 
they experience decreased motivation, difficulty in sleeping, feeling of helplessness, hopelessness, and resentment (Queen \& Harding, 2020; Tanhan et al., 2020). In addition to these issues, there is an emerging literature on the mental and physical exhaustion due to COVID-19 related restrictions. Scholars coined various terms such as "quarantine fatigue" (Marcus, 2020), "behavioral fatigue" (Harvey, 2020), "emergency/public/adherence fatigue" (Michie et al., 2020), "pandemic burnout" (Queen \& Harding, 2020), and "pandemic fatigue" (Michie et al., 2020; Murphy, 2020; WHO, 2020). As burnout depicts a situation related to work (Maslach \& Leiter, 2016), among these terms, we believe that "pandemic fatigue" can be the most appropriate concept. Initially, fatigue is defined as "the awareness of a decreased capacity for physical and/or mental activity due to an imbalance in the availability, utilization, and restoration of resources needed to perform activity" (Aaronson et al., 1999, p.46). Accordingly, pandemic fatigue is defined as the tendency for individuals to become wearied of rules and advisory, which should be followed to prevent the spread of COVID-19 (Michie et al., 2020; Murphy, 2020). Additionally, the WHO (2020) describes pandemic fatigue as demotivation to engage in protection behaviors and seek COVID-19 related information due to unresolved and continuous adversity in life. One possible explanation for pandemic fatigue relates to human physiologically. This explanation proposes that the human body release adrenaline at the onset of the pandemic which gives individuals enthusiasm and keenness to deal with the pandemic. However, the maintenance of adrenaline for an extended period of time is challenging for the human body (Murphy, 2020), especially given that the end of the pandemic is uncertain. Subsequently, the initial passion and eagerness diminish, and an overall exhaustion arises (Murphy, 2020). Other explanations of pandemic fatigue focus on the contributing role of social, environmental, and personal factors, such as social isolation (Zerbe, 2020), an overwhelming amount of COVID-19 news in the media (Teng et al., 2020), and self-care (Zou et al., 2020). Though there is a lack of studies focusing on pandemic fatigue in the general public, studies conducted with healthcare providers demonstrated that social support (Teng et al., 2020), moral responsibility to help others (Lilleholt et al., 2020), and psychological support (Sasangohar et al., 2020) helped the participants manage pandemic burnout and fatigue.

Harvey (2020) proposed that pandemic fatigue can manifest itself in various forms: individuals may refuse to comply with COVID-19-related regulations as they may (a) gradually become irritated with them, (b) believe regulations restrict their freedom, (c) incorrectly believe that COVID-19 is less dangerous than before, and (d) feel an overwhelming desire to socialize with others. Such fatigue may emerge gradually over time, be affected by personal emotions and experiences, as well as the cultural, social, and governmental systems (WHO, 2020). For instance, as time passes, individuals may become used to coronavirus's existence; therefore, the most extreme circumstances may become normal, and the perceived threat of the COVID-19 pandemic may decrease. Some individuals may also feel as though their freedom is being threatened as restrictions continue for an extended period of time, which may eventually manifest itself as pandemic fatigue.

The concept of pandemic fatigue has been studied among various populations with different terminology. For instance, in a cross-sectional study, Morgul et al. (2020) investigated psychological COVID-19-related fatigue in Turkey and found that $64.1 \%$ of participants reported having physical and mental fatigue. In this study, fatigue was described as feeling mentally and physically tired, lacking energy, inability to maintain daily activities, experiencing a decreased desire to complete tasks, difficulty thinking clearly and focusing on work (Morgul et al., 2020). Although this study demonstrated notable results, a fundamental flaw of this study was that the authors did not utilize a COVID19 specific instrument to assess participants' fatigue levels. Nitschke et al. (2020) conducted a study to examine the relationship between social connectedness and stress, worry, and fatigue during COVID-19 lockdown in Austria. This study's results showed a negative relationship between social connectedness and fatigue, which was mediated by individuals' perceived levels of stress and worry. This study also drew conclusions based on a global fatigue assessment.

Yıldırım and Solmaz (2020) developed a pandemic-specific reliable and valid assessment tool, called the COVID19 Burnout Scale, to measure adverse outcomes of COVID19 on individuals' mental health. Though burnout is mainly a work-related concept, this instrument is not work-specific and focuses on COVID-19-related pandemic fatigue. Several conceptual articles exist in the extant literature explaining what COVID-19-related pandemic fatigue is and what it looks like; however, there is a scarcity of scientific research conducted with assessments specific to COVID-19. Therefore, in this study, we use the COVID-19 Burnout Scale to measure and investigate pandemic fatigue and its relations to fear of COVID-19, intolerance of uncertainty, apathy, and self-care among the general public.

\section{Fear of COVID-19}

Despite the restrictions to prevent the spreading of COVID19 , such as isolation, social distancing, quarantine, and lockdown (Dsouza et al., 2020), the fear of coronavirus has emerged among individuals (Arpaci et al., 2021; Mamun \& Griffiths, 2020; Pakpour \& Griffiths, 2020). The fear of coronavirus is an emotion-centered psychological response 
to the COVID-19 outbreak (Pakpour et al., 2020). In some studies, fear of coronavirus is defined as the fear of getting infected or infecting loved ones and relatives (Colizzi et al., 2020; Mamun \& Griffiths, 2020), fear of experiencing serious physical illnesses related to the COVID-19 (Park \& Park, 2020), and fear of dying from the COVID-19 (Ornell et al., 2020; Shigemura et al., 2020; Xiang et al., 2020). Researchers stated that the presence of infected people in the vicinity increases coronavirus fear (Ornell et al., 2020). Several researchers concluded that the level of coronavirus fear is higher among women (Bitan et al., 2020; Haktanir et al., 2020), families with children, individuals living in crowded cities with higher COVID-19 cases (Fitzpatrick et al., 2020), individuals from low-income families, students, individuals who lost their relatives due to COVID-19, individuals with chronic diseases, and those who identify themselves in the risk groups (Bitan et al., 2020; Reznik et al., 2020). Additionally, researchers proposed that false information obtained from social media (Lin et al., 2020) and stigmatization (Person et al., 2004) may increase fear.

The fear of coronavirus may trigger several psychological problems such as anxiety, depression, phobias, and eating disorders (Colizzi et al., 2020; Soraci et al., 2020). Additionally, the fear of coronavirus may exacerbate pre-existing psychological disorders (Colizzi et al., 2020), lead to insomnia (Lin et al., 2020), and even suicide attempts (Dsouza et al., 2020; Mamun \& Griffiths, 2020). Although COVID19-related fear might have potentially motivated individuals to take more precautions at the onset of the pandemic, given the length of the pandemic, we believe that individuals with greater coronavirus fear would be mentally more exhausted at this time, which could lead to higher pandemic fatigue. Individuals with high coronavirus fear may be inclined to confront the fear and stop it altogether due to prolonged mental engagement with coronavirus. Accordingly, we hypothesize that individuals with greater fear of COVID-19 would show higher pandemic fatigue (Hypothesis 1).

\section{Intolerance of uncertainty}

Uncertainties about how long the COVID-19 pandemic will last (Gica et al., 2020; Glowacz \& Schmits, 2020), how the virus is being transmitted (McKay et al., 2020), how long government restrictions will last (Rettie \& Daniels, 2020), what will happen due to limited tests during the pandemic (Mertens et al., 2020), and what will happen in the future (Larsen et al., 2020) are some of the questions raised by researchers, scientists, and the public. These questions illustrate the uncertainty of the pandemic (Freeston et al., 2020; Koffman et al., 2020) and may be troubling for many individuals (Arpaci et al., 2021), especially for those with low tolerance of certainty. Intolerance of uncertainty is a cognitive bias that affects how individuals perceive, interpret, and react to uncertain situations at behavioral, mental, and emotional levels (Dugas et al., 2005). Intolerance of uncertainty is also defined as subjective negative emotions experienced in response to unknown aspects of a situation (Carleton, 2012; Freeston et al., 2020). During the COVID19 pandemic, intolerance of uncertainty increases due to changes in daily routines (Satici et al., 2020).

Researchers also highlighted the association between psychopathological symptoms and intolerance of uncertainty among the public (Del Valle et al., 2020). To exemplify, as individuals' intolerance of uncertainty increased, their psychosomatic complaints (Gica et al., 2020), anxiety, depression levels (Glowacz \& Schmits, 2020; Rettie \& Daniels, 2020), obsessive and physical tendencies (McKay et al., 2020), insomnia symptoms (Voitsidis et al., 2020), and signs of loneliness (Parlapani et al., 2020) increased. Additionally, Larsen et al. (2020) reported that individuals with higher intolerance of uncertainty tended to present more symptoms of paranoia, conspiratorial thoughts, and delusions. An increased level of fear of coronavirus was found to be associated with greater intolerance of uncertainty (Bakioğlu et al., 2020; Parlapani et al., 2020). Given the uncertainty and ambiguity about coronavirus, we believe that this state may increase mental exhaustion for those with low tolerance of uncertainty. When individuals experience high intolerance of uncertainty, their ability and motivation to deal with COVID-19 and take necessary precautions to protect themselves may decrease. Therefore, we expect individuals with greater intolerance of uncertainty to experience more significant pandemic fatigue (Hypothesis 2).

\section{Apathy and self care}

Apathy is defined as a state of inertia in which no stimulation can create a feeling and loss of motivation in goal-oriented behavior with reduced emotional expression (Alexopoulos, 2020; Gürvit, 2014; Marin, 1990; Skorvanek et al., 2013; Van Reekum et al., 2005). Apathy is a symptom of emotional deprivation and burnout, as well as a psychological response to stressful events in life (Jha et al., 2020; Levy et al., 1998; Marin et al., 1991). As individuals' motivation levels decrease during the pandemic, their apathetic behavior increases (Jakhar \& Kaur, 2020). Sultanov et al. (2020) identified these increased behaviors, as decreased facial expressions, deprivation of self-expression skills, monotonous speech, and slow movements. Foa et al. (2020) noted that as individuals' apathy levels increased, their life satisfaction decreased. Given that apathy is defined as emotional deprivation and burnout, we hypothesized that individuals with greater apathy would experience higher pandemic fatigue (Hypothesis 3). 
Self-care is an essential protective factor for disease prevention and defined as an ability to promote and maintain health without a healthcare provider (World Health Organization Regional Office for South-East Asia, 2009). During the pandemic, self-care activities increase the quality of life and decrease the pandemic's negative impact on individuals' mental health (Adams et al., 2020; Queen \& Harding, 2020). Researchers reported a positive relationship between self-care and individuals' psychological well-being (Gal et al., 2020; Mak, 2009; Moreno et al., 2020). Additionally, scholars recommended individuals develop self-care habits to protect their mental health during and after the pandemic (Adams et al., 2020; Murthy, 2020). To develop self-care activities, individuals may create daily routines, interact with those around them, stay active, and engage in entertaining activities (Peteet, 2020). Finally, mental health professionals suggest that self-care can be a protective factor in preventing pandemic fatigue (CBS New York, 2020). Therefore, we hypothesized that self-care could be a mediating variable in explaining COVID-19-related pandemic fatigue (Hypothesis 4).

\section{Method}

\section{Participants}

In the present study, we recruited 516 adults across Turkey. Due to incomplete data, we removed 16 cases, resulting in a total of 500 remaining participants. Participants were between the ages of 18 and $68(M=27.33, S D=$ 9.83). Of these participants, $73.20 \%(N=366)$ identified as female and $26.8 \%(N=134)$ identified as men. When we inspected the age range of the participants, $71.40 \%(N$ $=357$ ) of those reported being at the age between 18 to 29 years old, $23.60 \%(N=118)$ of those reported being at the age between 30 to 49 years old, while the rest of the participants $(N=25 ; 5 \%)$ reported being 50 years old and older. Additionally, when we compared the degree to which the participants took protective measures in the early days of the pandemic to the measures taken at the time of data collection, $34.40 \%$ of the participants $(N=$ $172)$ reported taking fewer precautions in comparison to early days, while $19.00 \%(N=95)$ reported taking more precautions during data collection. Also, $46.60 \%$ of the participants $(\mathrm{N}=233)$ marked "no differences" for this question. Lastly, $56.20 \%$ of the participants $(\mathrm{N}=281)$ reported having acquaintances with COVID-19, while $43.80 \%(\mathrm{~N}=219)$ reported knowing no individuals diagnosed with COVID-19 (see Table 1).
Table 1 Characteristics of Participants

\begin{tabular}{lll}
\hline Variables & $N$ & $\%$ \\
\hline Gender & & \\
Women & 366 & 73.20 \\
Men & 134 & 26.80 \\
Age range & & \\
Between 18-29-year-olds & 357 & 71.40 \\
Between 30-39-year-olds 30-39 & 65 & 13.00 \\
Between 40-49-year-olds 40-49 & 53 & 10.60 \\
Between 50-59-year-olds 50-59 & 22 & 4.40 \\
60-year-olds and older & 3 & 0.60 \\
Differences in measures taken & & \\
Less nowadays & 172 & 34.4 \\
No difference & 233 & 46.60 \\
More nowadays & 95 & 19.00 \\
Knowing someone diagnosed with COVID- & & \\
$\quad$ 19 & & \\
Yes & 281 & 56.20 \\
No & 219 & 43.80 \\
Total & 500 & 100 \\
\hline
\end{tabular}

\section{Procedures}

Upon the arrival of the IRB ethical approval, we created an online survey consisting of an informed consent form, demographic questionnaire, the COVID-19 Burnout Scale, the Intolerance of Uncertainty Scale, the Apathy Evaluation Scale, the Fear of COVID-19 Scale, and the Exercise of Self-Care Agency Scale. The survey link was then distributed to potential participants via email, social media (e.g., WhatsApp, Facebook), and other online data dissemination platforms. Additionally, using the snowball sampling method, the participants were asked to share the survey with others. Once data collection was finalized, we downloaded the data into an Excel sheet and transferred it to the SPSS. The survey was available from November 1 until November 12, 2020, during which COVID-19 vaccination was not available in Turkey. In fact, no COVID-19 vaccines were approved for use in the world during the data collection period of this study. Turkey started administering COVID-19 vaccinations to the public months after our data collection.

\section{Demographic questionnaire}

We developed a questionnaire to assess participants' various demographic information including gender, age, whether someone close was diagnosed with COVID-19, and the differences in measures taken. 


\section{The COVID-19 burnout scale (COVID-19-BS)}

The COVID-19-BS is the Turkish version of the Burnout Measure-Short Version, which was originally developed by Malach-Pines (2005). Yıldırım and Solmaz (2020) tailored the Turkish version of the scale to measure individuals' coronavirus burnout level. The COVID-19-BS is a 10-item selfreport assessment with a 5-point Likert-type scale $(1=$ never and $5=$ always). Individuals respond to questions such as "When you think about coronavirus in general, how often do you feel tired?". In this scale, possible scores range from 10 to 50 . Item factor loads of the scale vary between 0.58 and 0.88 , and the Cronbach's alpha internal consistency coefficient of the Turkish form of the scale was .92. See Table 2 for reliability values for the current study.

\section{Intolerance of uncertainty (IUS-12)}

The IUS-12 was developed to measure individuals' level of tolerance against the uncertainties in their lives (Carleton et al., 2007). Sarıçam et al. (2014) translated and adapted the scale into the Turkish language. The ISU-12 is a 12 -item self-report assessment with a 5 -point Likert-type scale $(1=$ not suitable for me and $5=$ completely appropriate for me). Individuals respond to statements such as "'Unexpected events bother me a lot". In this scale, possible scores range from 12 to 60 . The scale consists of two sub-dimensions: anticipatory and inhibitory anxiety. Item factor loads of the scale vary between 0.55 and 0.87 . The Cronbach's alpha internal consistency coefficient of the subscales was .84 for the anticipatory anxiety, and .77 for the inhibitory anxiety sub-dimension. The Cronbach's alpha coefficient was .88 for the whole scale.

\section{Apathy evaluation scale (AES)}

The Apathy Evaluation Scale (AES; Marin et al., 1991) is a Likert-type instrument assessing individuals' motivation to perform everyday tasks. Gülseren et al. (2001) translated and adapted the scale into the Turkish language. The scale has three versions: clinician, informant, and self-rated. In this study, we utilized the self-rated version consisting of 18 items such as "S/he is interested in having new experiences".
Participants rate their responses on a 4-point Likert-type scale $(1=$ not at all characteristic and $4=$ a lot characteristic). In this scale, possible scores range from 18 to 72 , with higher scores indicating greater levels of apathy. In the Turkish version of the AES, Cronbach's alpha coefficient score was .94.

\section{The fear of COVID-19 scale (FCV-19S)}

The FCV-19S was developed by Ahorsu et al. (2020) to assess individuals' level of coronavirus fears. Haktanir et al. (2020) translated and adapted the scale to the Turkish language. The scale consists of 7 items, such as "It makes me uncomfortable to think about coronavirus". The FCV-19S is a self-report assessment with a 5-point Likert-type scale ( $1=$ strongly disagree and $5=$ strongly agree). For this scale, possible scores range from 7 to 35 , a higher total score indicates a greater level of coronavirus fear. Item factor loads of the scale vary between .50 and .81 . The Cronbach's alpha coefficient for the Turkish form was .86, and the split-half reliability score was .83 .

\section{The exercise of self-care agency scale (ESAS)}

The ESAS, developed by Kearney and Fleischer (1997), measures individuals' self-care practices. The translation and adaptation of the scale into the Turkish language was carried out by Nahcivan (1993). The scale consists of 35 items, such as "I often feel that I lack the energy to care for my health needs the way I would like to". The ESAS is a self-report assessment with a 5 -point Likert-type scale $(0=$ does not describe me at all and $4=$ describes me completely). In this scale, possible scores range from 0 to 140 . For the Turkish version of the ESAS, the KR-20 value was .92, and the testretest correlations were between .80 and .90 .

\section{Data analysis}

After transferring data to SPSS, we carried out data cleaning, prepared data for analysis, tested the assumptions, calculated descriptive statistics, and carried out the primary analysis. We utilized the SPSS Amos Graphics (version 19.0) to run a structural equation modeling. We selected the following
Table 2 Descriptive statistics and correlation coefficients

\begin{tabular}{llllllll}
\hline & $\mathrm{a}$ & $\mathrm{M}$ & $\mathrm{SD}$ & 1 & 2 & 3 & 4 \\
\hline Coronavirus Fear & .90 & 17.79 & 6.18 & - & & \\
Intolerance of Uncertainty & .91 & 39.98 & 10.54 & $.34^{* *}$ & - & & \\
Self-care & .93 & 100.84 & 21.97 & .04 & -.03 & - & \\
Apathy & .88 & 28.70 & 7.90 & -.01 & .01 & $-.63^{* *}$ & - \\
Pandemic Burnout & .93 & 26.19 & 9.62 & $.53^{* *}$ & $.42^{* *}$ & $-.12^{* *}$ & .04 \\
\hline
\end{tabular}

$* * \mathrm{p}<.01$ 
criteria for goodness of fit: $\chi^{2} / \mathrm{df}<5$; RMSEA, SRMR $<0.08$; NFI, GFI, CFI, TLI $\geq 0.90$ (Brown, 2006; Kline, 2005; Schumacker \& Lomax, 2010). To mitigate measurement errors, we utilized a randomized item parceling (Rocha \& Chelladurai, 2012; Williams et al., 2009).

\section{Results}

We conducted descriptive, correlational, and structural equation modelling (SEM) analyses to ascertain the values for each variable as well as interrelationships between and among variables. In the SEM, we examined the direct effects of coronavirus fear, intolerance of uncertainty on pandemic fatigue. Since we were unable to detect a significant correlation between apathy and COVID-19 fatigue, we gauged the indirect effect of apathy on coronavirus fatigue as mediated by self-care.

\section{Descriptive statistics, reliability estimates, and correlations}

In this study, Cronbach alpha values for the COVID-19 Scale, the Self-Care Agency Scale, the Apathy Evaluation Scale, the Intolerance of Uncertainty, and for COVID-19 Burnout Scale were $.90, .93, .88, .91, .93$, respectively. We observed positive moderate correlations between coronavirus fatigue and coronavirus fear $(r=0.53, p<.001)$, and coronavirus fatigue and intolerance of uncertainty $(r=0.44$, $p<.001)$. Self-care $(r=-0.12, p<.001)$ and pandemic fatigue demonstrated a negative weak correlation. The findings also showed a negative and strong relationship between apathy and self-care $(r=-0.63, p<.01)$, see Table 2 .

\section{Measurement model}

The model analysis was conducted in two steps. First, we tested the structural model that we created following the measurement model. The measurement model consisted of five latent variables (i.e., coronavirus fear, intolerance of uncertainty, self-care, apathy, and pandemic fatigue) and 13 indicators (two parcels for coronavirus fear and intolerance of uncertainty; three for self-care, apathy, and pandemic burnout). A confirmatory factor analysis showed good model fit (Byrne, 2010; Kline, 2005), $f^{2} / d f=2.60$, GFI= 0.96; $\mathrm{CFI}=0.98 ; \mathrm{NFI}=0.96 ; \mathrm{TLI}=0.97 ; \mathrm{SRMR}=0.04$; RMSEA $=0.06$. In this analysis, the standardized factor loadings for the indicators ranged between .75 and $.96(p<$ .001 ), meaning that the indicators significantly represented the latent variables.

\section{Structural model}

The effects of coronavirus fear, intolerance of uncertainty, self-care, and apathy on coronavirus fatigue were examined. This model revealed that COVID-19 fear, intolerance of uncertainty, and self-care had direct effect while apathy had an indirect effect on pandemic fatigue, see Figure 1 for the model. The structural model indicated excellent to acceptable goodness-of-fit indices (Byrne, 2010, Kline, 2005), $\chi^{2} /$ $d f=3.53, \mathrm{GFI}=0.94 ; \mathrm{CFI}=0.96 ; \mathrm{NFI}=0.95 ; \mathrm{TLI}=0.95$; SRMR $=0.08$; RMSEA $=0.07$, see Table 2 for effect values. Furthermore, this model demonstrated that COVID-19 fear, intolerance of uncertainty, and self-care had direct effects on COVID-19 fatigue, $\beta=0.53, \beta=0.30$, and $\beta=-0.14$, respectively. Additionally, apathy had an indirect effect on pandemic fatigue, which was mediated by participants' level of self-care. Finally, squared multiple correlation values $\left(R^{2}\right)$
Fig. 1 Selected structural model depicting the relations between COVID-19 burnout, COVID-19 fear, intolerance of uncertainty, self-care, and apathy.

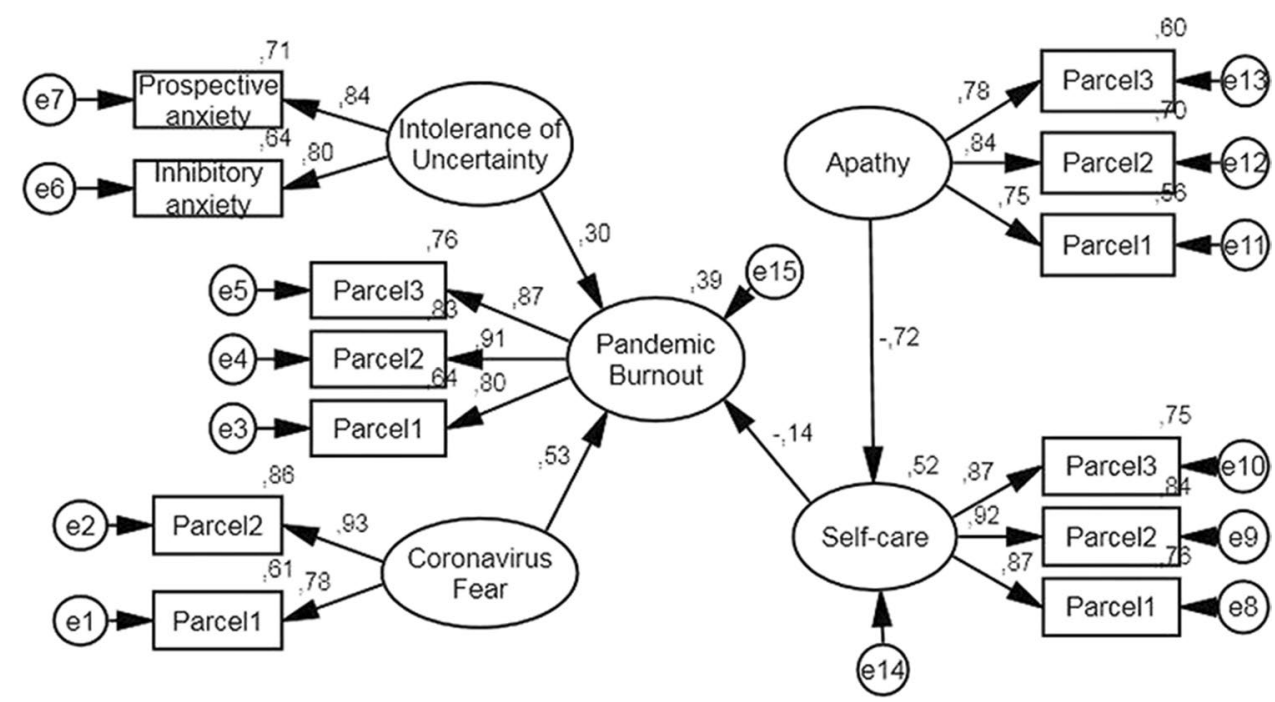


indicated that the predictor variables explained $39.4 \%$ of the variance in pandemic fatigue scores, see Table 3.

\section{Discussion}

As we acknowledged the anniversary of the COVID-19 pandemic in December 2020 worldwide and in March 2021 in Turkey, the ambiguity related to when the pandemic will be over still remains a mystery. Given the longevity of the pandemic, many individuals may be experiencing pandemic fatigue. Though it is a concept discussed in many news reports, reviews, and conceptual articles, there is a lack of empirical evidence related to pandemic fatigue and its contributing factors. Therefore, the purpose of this study was to investigate the extent to which individuals experience pandemic fatigue and its relationship to fear of coronavirus, intolerance of uncertainty, apathy, and self-care. We proposed that these variables would significantly explain the variation in pandemic fatigue scores.

First, we examined participant responses to ascertain the degree of precautions taken currently and whether this degree differs from how much precautions taken when the pandemic started. One in every three participants reported exercising less caution when compared to the early days of the pandemic, which appears counterintuitive as the number of confirmed COVID-19 cases and deaths are unprecedentedly high. It is important to note that data collection of this study was carried out in early November 2021, during which no vaccinations were approved for use in the world. Second, bivariate correlation analyses showed a significant correlation between pandemic fatigue and fear of coronavirus, intolerance of uncertainty, and self-care. However, contrary to our initial hypothesis, there was no significant correlation between pandemic fatigue and apathy. Apathy, however, had a high negative correlation with self-care. Hayes (2018) suggested that a mediator analysis can be conducted even when a predictor variable is not correlated with the outcome variable. Therefore, we completed our primary analysis only examining the indirect effect of apathy mediated by self-care on pandemic fatigue.

Our model examining the role of fear of coronavirus, intolerance of uncertainty, and apathy mediated by selfcare predicting pandemic fatigue demonstrated acceptable to excellent goodness-of-fit indices. Considering the contributions of all variables in this study, our model accounted for $39.4 \%$ of the variance in pandemic scores, which can be interpreted as a large effect size (Field, 2013). Therefore, this model suggests that participants with higher scores in fear of coronavirus and intolerance of uncertainty tended to report more significant pandemic fatigue.

\section{Hypothesis 1}

First, fear of COVID-19 was a significant predictor of pandemic fatigue. As participants' coronavirus fear increased, they tended to experience greater levels of pandemic fatigue. This predictive relationship may be explained by our initial hypothesis that individuals with higher levels of coronavirus fear may feel overwhelmed. This situation may manifest itself as pandemic fatigue, which may lead to decreased compliance with regulations.

\section{Hypothesis 2}

Second, our results showed that individuals with higher intolerance of uncertainty reported experiencing higher pandemic fatigue. Though researchers have suggested an association between intolerance of uncertainty during the COVID-19 era and various psychological issues, such as psychosomatic complaints, anxiety, and depression (Gica et al., 2020; Glowacz \& Schmits, 2020), this is the first study to our knowledge examining the association between pandemic fatigue and intolerance of uncertainty. The role of intolerance of uncertainty in explaining pandemic fatigue might be explained by that individuals with greater intolerance of uncertainty can be negatively affected by ambiguity pertaining to the unfolding of the pandemic. Specifically, individuals with high intolerance of uncertainty may feel overwhelmed by the rapidly changing flow of life during the pandemic, as little structure is provided by the governments. Given that certain criteria are not established regarding when would a full-lockdown, partial-lockdown (e.g., only weekend lockdowns), suspension of face-to-face schooling, and closure of businesses, such factors may be exacerbating the pandemic fatigue among those experiencing high intolerance of uncertainty.

Table 3 Direct effect values

\begin{tabular}{llll}
\hline Path & Standardized $\beta$ & $S E$ & Critical Value \\
\hline Coronavirus Fear $\rightarrow$ Pandemic Burnout & 0.53 & 0.06 & $10.32^{* *}$ \\
Intolerance of Uncertainty $\rightarrow$ Pandemic Burnout & 0.30 & 0.03 & $5.83^{* *}$ \\
Self-care $\rightarrow$ Pandemic Burnout & -0.14 & 0.02 & $-3.37^{* *}$ \\
Apathy $\rightarrow$ Self-care & -0.72 & 0.13 & $-13.79^{* *}$ \\
\hline
\end{tabular}

$* * p<0.01$ 


\section{Hypothesis 3}

Third, a bivariate correlation analysis between apathy and pandemic fatigue refuted our third hypothesis. This may be explained by the nature of fatigue. Fatigue is an adverse side effect of behaving in a certain manner over a period of time that this process becomes unbearable (Harvey, 2020). Harvey (2020) proposed the analogy that fatigue is like muscle tiredness. The more one uses it, over time, the more it hurts. As a result, at some point, individuals may give up on taking precautions. The dialect between apathy and fatigue may stem from the notion that individuals with high apathy may not show sufficient care to feel fatigued. In other words, they may not have cared about COVID-19 and restrictions in the first place and may not have developed pandemic fatigue.

\section{Hypothesis 4}

Finally, scholars stress the importance of self-care in preventing negative mental health impacts of the COVID-19 pandemic (Adams et al., 2020; Queen \& Harding, 2020). To ascertain whether self-care could help individuals decrease potential pandemic fatigue, we tested the mediator role of self-care between apathy and pandemic fatigue. Our model suggested that as apathy decreased, individuals' level of self-care increased, and as their self-care increased participants' level of pandemic fatigue decreased. In other words, we were unable to find a significant relationship between pandemic fatigue and apathy; however, the significant mediating relationship can be interpreted as that individuals with low apathy scores showed significantly greater self-care practices which decreased pandemic fatigue. Researchers (e.g., Padala et al., 2008) reported that individuals reporting high apathy were less likely to maintain an exercise and self-care plan. As reported earlier, individuals experiencing high levels of apathy lack motivation to engage in goal-oriented behaviors and exhibit reduced emotional expression (Alexopoulos, 2020). Subsequently, such a low motivation can manifest itself as disconnection from all goal-oriented behaviors, including self-care. Finally, given that apathy is associated with decreased emotional expression, increased apathy paired with low self-care may be overwhelming for individuals as there would be a lack of mechanism to vent negative emotions. Such overwhelming emotions may lead to stop taking precautions to protect oneself against COVID19 , as individual may no longer care about getting infected.

\section{Implications}

In our study, $34.40 \%$ of the participants reported that the level of precautions they take has decreased in comparison to measures they took at the onset of the pandemic. Such a tendency is not only a threat to individuals' health but also to the general public. Our findings may be interpreted as that regardless of the restrictions imposed by governments, the biopsychosocial nature of humans should be taken into account in fighting against COVID-19. Such an approach is important as merely focusing individual or broader context may be limited in addressing pandemic fatigue. Considering the Ecological System Theory, we provided implications for both individuals and governments related to pandemic fatigue.

First, while governments predominantly focus on preventing the spread of the pandemic by ordering restrictions, such as lockdowns and reduced shopping hours, in addition to those precautions, we suggest legislators take the psychological factors (e.g., pandemic fatigue) into account when fighting against COVID-19. One way to achieve this could be to make mental health services to the public more accessible and affordable. Increased access to mental health services may help individuals to have a psychologically more balanced approach toward COVID-19. Additionally, many countries are in some type of restriction and lockdown (e.g., full-lockdown, lockdown during certain hours). Governments can establish scientific criteria for imposition of and lifting restrictions. For example, based on scientific studies and experiences in other states, legislators can identify a certain number of daily coronavirus cases to impose and lift partial or full restrictions, including lockdowns, closures of schools, and businesses. This approach could increase predictability and may reduce pandemic fatigue, as uncertainty would be decreased.

Additionally, the WHO (2020) proposed strategies for nations to fight against pandemic fatigue and stressed the pivotal role of understanding the psychological reactions of individuals, allowing the public to maintain their lives while reducing risk, and recognizing the difficulty experienced by individuals. WHO (2020) also suggested several principles in reducing public fear and increasing predictability: (a) transparency, which stresses the significance of sharing accurate information to prevent confusion and conspiracy theories; (b) fairness, which is about acknowledging the needs of all; (c) consistency, which refers to the alignment between the actions of leaders and what is required of the citizens; (d) coordination, which refers to consistent answers by the leaders, and; (e) predictability, which emphasizes identifying "objective epidemiological criteria for restrictions" (WHO, 2020, p. 22-23). It is evident from the recommendation of the WHO that governments should take into account several factors in preventing pandemic fatigue, including attending to the reaction of the public, being transparent and consistent, paying attention to the individual needs, and considering the sustainability of the restrictions in terms of psychological factors, including COVID-19-related fatigue. 
Furthermore, results of the current study revealed that pandemic fatigue can be predicted by COVID-19 fear, intolerance of uncertainty, and apathy as mediated by self-care. These findings imply that when individuals are overwhelmed with intense emotions due to increased fear and lack of tolerance for uncertainty, their ability to cope with the pandemic diminishes. We also found that self-care can mitigate the level of pandemic fatigue as a protective factor. Therefore, individuals should intentionally practice self-care (e. g., home exercise, healthy diet, regular sleep) to prevent fatigue while exercising precautions, such as wearing a mask and practicing physical distance. Finally, given the predictive role of fear of COVID-19 and pandemic fatigue, the media and other news sources should consider the psychological effects of (e.g., fear) the way in which news is covered. Attention should be given to urging the public to protect themselves against the virus, not scaring them, and conveying only accurate information.

\section{Limitations and recommendations for future research}

Overall, this study discussed the present state of pandemic fatigue and factors contributing to this phenomenon. However, several limitations warrant further discussion. First, we used a cross-sectional sample that involved collecting data from participants at once. Therefore, our results should be interpreted as an association, not causation. Longitudinal studies as well as qualitative (e.g., phenomenological, Online Photovoice) and mixed method studies are warranted to explore the phenomena more in-depth. Second, although we reached out to different age groups, approximately half of our participants were under 25 . This could create an agebias in our findings. Thus, we recommend future researchers to recruit more heterogeneous samples in terms of age. Third, we collected data using self-report instruments. Such instruments usually reflect the perception of the participants, which may or may not reflect what the participants were actually experiencing. Given that we used a snowball sampling method, social desirability is a bias risk. Therefore, we recommend future researchers to collect data using the cluster sampling method representative of all age groups. Fourth, we employed an online data collection method. Though it seems to be the best option given the circumstances, it limits our sample to individuals with Internet access. Fifth, 26 participants (5.20\%) were diagnosed with COVID-19. Though this group constituted a small portion of the participants, it is possible that these participants might have felt that they no longer needed to practice caution to protect themselves from coronavirus as they may feel immunized. We could not find a statistically significant difference between those diagnosed with COVID-19 and those without a COVID-19 diagnosis, though such a finding could be due to a small sample in the group with a diagnosis $(n=26)$. Future researchers can only recruit participants without a COVID-19 diagnosis, as such a diagnosis can directly be related to the extent to which one can protect themselves from COVID-19. Finally, the structural equation model tested in the present study is one of many potential models. Given that this study did not test a particular theoretical framework, future researchers can examine this phenomenon with a theoretical lens using theory-based models or experimental designs.

\section{Conclusions}

In this study, we examined the current state of pandemic fatigue and the predictive role of fear of COVID-19, intolerance of ambiguity, and apathy as mediated by self-care in explaining pandemic fatigue. Pandemic fatigue is a crucial topic as the existence of which could threaten both individuals and public health. Our findings demonstrated that coronavirus fear and intolerance of ambiguity directly affected pandemic fatigue while apathy was mediated by self-care. Despite the existence of reviews and conceptual articles, to our knowledge, this is the first empirical study examining pandemic fatigue.

Supplementary Information The online version contains supplementary material available at https://doi.org/10.1007/s12144-021-02397-w.

Funding This research did not receive any specific grant from funding agencies in the public, commercial, or not-for-profit sectors.

Data Availability All data generated or analyzed during this study are included in this published article and its supplementary information files.

\section{Declaration}

Disclosure statement We report no potential conflict of interest.

Ethical approval All procedures employed in the current investigation were in accordance with the ethics committee application and with the Belmont Report-1979. Necmettin Erbakan University Social Sciences Research Ethics Committee decision number: 2020/100.

\section{References}

Aaronson, L. S., Teel, C. S., Cassmeyer, V., Neuberger, G. B., Pallikkathayil, L., Pierce, J., Press, A., \& N., Williamsü P. D., Wingate, A. (1999). Defining and measuring fatigue. Journal of Nursing Scholarship, 31(1), 45-50.

Adams, M., Chase, J., Doyle, C., \& Mills, J. (2020). Self-care planning supports clinical care: Putting total care into practice. Science and the Art of Caring, 28(5), 305-307. https://doi.org/10.1080/09699 260.2020.1799815

Ahorsu, D. K., Lin, C. Y., Imani, V., Saffari, M., Griffiths, M. D., \& Pakpour, A. H. (2020). The fear of COVID-19 scale: Development 
and initial validation. International Journal of Mental Health and Addiction. https://doi.org/10.1007/s11469-020-00270-8

Alexopoulos, G. S. (2020). Neurobiological targets of apathy can guide treatment development. The American Journal of Geriatric Psychiatry. https://doi.org/10.1016/j.jagp.2020.06.023

Arpaci, İ., Karataş, K., \& Baloğlu, M. (2020). The development and initial test for the psychometric properties of the COVID-19 phobia scale (C19P-S). Personality and Individual Differences. Advance Online Publication. https://doi.org/10.1016/j.paid.2020. 110108

Arpaci, İ., Karatas, K., Baloglu, M., \& Haktanir, A. (2021). COVID-19 phobia in the United States: Validation of the COVID-19 phobia scale (C19P-SE). Death Studies. Advance Online Publication. https://doi.org/10.1080/07481187.2020.1848945

Bakioğlu, F., Korkmaz, O., \& Ercan, H. (2020). Fear of COVID-19 and positivity: Mediating role of intolerance of uncertainty, depression, anxiety, and stress. International Journal of Mental Health and Addiction. https://doi.org/10.1007/s11469-020-00331-y

Bandalos, D. L. (2002). The effects of item parceling on goodness-offit and parameter estimate bias in structural equation modeling. Structural Equation Modeling, 9(1), 78-102. https://doi.org/10. 1207/S15328007SEM0901_5

Bitan, D. T., Grossman-Giron, A., Bloch, Y., Mayer, Y., Shiffman, N., \& Mendlovic, S. (2020). Fear of COVID-19 scale: Psychometric characteristics, reliability and validity in the Israeli population. Psychiatry Research, 289. https://doi.org/10.1016/j.psychres. 2020.113100

Bronfenbrenner, U. (1977). Toward an experimental ecology of human development. American Psychologist, 32, 513-531. https://doi. org/10.1037/0003-066X.32.7.513

Brown, T. A. (2006). Confirmatory factor analysis for applied research. Guilford Press.

Carleton, R. N. (2012). The intolerance of uncertainty construct in the context of anxiety disorders: Theoretical and practical perspectives. Expert Review of Neurotherapeutics, 12(8), 937-947. https://doi.org/10.1586/ern.12.82

Carleton, R. N., Norton, M. P. J., \& Asmundson, G. J. (2007). Fearing the unknown: A short version of the Intolerance of Uncertainty Scale. Journal of Anxiety Disorders, 21(1), 105-117. https://doi. org/10.1016/j.janxdis.2006.03.014

CBS New York. (2020). Pandemic burnout: Experts stress the importance of self-care and supporting others. Retrieved from https:// newyork.cbslocal.com/video/4801960-pandemic-burnout-exper ts-stress-importance-of-self-care-and-supporting-others/

Ceri, V., \& Cicek, I. (2021). Psychological well-being, depression and stress during COVID-19 pandemic in Turkey: A comparative study of healthcare professionals and non-healthcare professionals. Psychology, Health \& Medicine, 26(1), 85-97. https://doi.org/ 10.1080/13548506.2020.1859566

Colizzi, M., Bortoletto, R., Silvestri, M., Mondini, F., Puttini, E., Cainelli, C., et al. (2020). Medically unexplained symptoms in the times of Covid-19 pandemic: A case-report. Brain, Behavior, and Immunity-Health. https://doi.org/10.1016/j.bbih.2020.100073

Del Valle, M. V., Andrés, M. L., Urquijo, S., Yerro-Avincetto, M., López-Morales, H., \& Canet-Jurica, L. (2020). Intolerance of uncertainty over COVID-19 pandemic and its effect on anxiety and depressive symptoms. Revista Interamericana de Psicologíal Interamerican Journal of Psychology, 54(2), 1-17.

Dsouza, D. D., Quadros, S., Hyderabadwala, Z. J., \& Mamun, M. A. (2020). Aggregated COVID-19 suicide incidences in India: Fear of COVID-19 infection is the prominent causative factor. Psychiatry Research, 290. https://doi.org/10.1016/j.psychres.2020.113145

Dugas, M. J., Hedayati, M., Karavidas, A., Buhr, K., Francis, K., \& Phillips, N. A. (2005). Intolerance of uncertainty and information processing: Evidence of biased recall and interpretations.
Cognitive Therapy and Research, 29(1), 57-70. https://doi.org/ 10.1007/s10608-005-1648-9

Emir Öksüz, E., Kalkan, B., Can, N., \& Haktanir, A. (2021). Adult mental health and loneliness during the COVID-19 pandemic in late 2020. European Journal of Psychology Open, 80, 1-13. https://doi.org/10.1024/2673-8627/a000001

Field, A. (2013). Discovering statistics using IBM SPSS Statistics. ( $4^{\text {th }}$ ed.), SAGE.

Fitzpatrick, K. M., Harris, C., \& Drawve, G. (2020). Fear of COVID19 and the mental health consequences in America. Psychological Trauma: Theory, Research, Practice, and Policy, 12(1), 17-21. https://doi.org/10.1037/tra0000924

Foa, R., Gilbert, S., \& Fabian, M. O. (2020). COVID-19 and subjective well-being: Separating the effects of lockdowns from the pandemic. The Lancet. https://doi.org/10.2139/ssrn.3674080

Freeston, M. H., Tiplady, A., Mawn, L., Bottesi, G., \& Thwaites, S. (2020). Towards a model of uncertainty distress in the context of Coronavirus (Covid-19). Uncertainty Distress in Covid-19.

Gal, T. B., Avraham, B. B., Abu-Hazira, M., Frigerio, M., CrespoLeiro, M. G., Oppelaar, A. M., et al. (2020). The consequences of the COVID-19 pandemic for self-care in patients supported with a Left Ventricular Assist Device. European Journal of Heart Failure. https://doi.org/10.1002/ejhf.1868

Gica, S., Kavakli, M., Durduran, Y., \& Ak, M. (2020). The effect of COVID-19 pandemic on psychosomatic complaints and investigation of the mediating role of intolerance to uncertainty, biological rhythm changes and perceived COVID-19 threat in this relationship: A web-based community survey. Psychiatry and Clinical Psychopharmacology, 30(2), 89-96. https://doi. org/10.5455PCP20200514033022

Glowacz, F., \& Schmits, E. (2020). Uncertainty and psychological distress during lockdown during the COVID-19 Pandemic: The young adults most at risk. Psychiatry Research, 29, 1-4. https:// doi.org/10.1016/j.psychres.2020.113486

Gülseren, G., Atun, Ç., Erol, A., Aydemir, Ö., Çelebisoy, M., \& Kültür, S. (2001). Apati Degerlendirme Ölçegi Türkçe formunun geçerlilik ve güvenilirlik çalışması [The validity and reliability study of the Turkish version of the Apathy Assessment Scale]. Nöropsikiyatri Arsivi [Neuropsychiatry Archive], 38(3), $142-150$.

Gürvit, I. H. (2014). Sosyal kognisyon veya fakülte psikolojisinin diyalektik sentezi olarak bir mental psikoloji/nörolojiye doğru [Social Cognition or Towards a Mental Psychology/Neurology as a Dialectical Synthesis of Faculty Psychology]. Noro-Psikyatri Arsivi [Archives of Neuropsychiatry], 51(4), 298-302. https://doi. org/10.5152/npa.2014.99

Haktanir, A., Seki, T., \& Dilmaç, B. (2020). Adaptation and evaluation of Turkish version of the fear of COVID-19 Scale. Death Studies, 1-9. https://doi.org/10.1080/07481187.2020.1773026

Harvey, N. (2020). Behavioral fatigue: Real phenomenon, naïve construct, or policy contrivance? Frontiers in Psychology, 11, 589892. https://doi.org/10.3389/fpsyg.2020.589892

Hayes, A. F. (2018). Introduction to mediation, moderation, and conditional process analysis: A regression-based approach $\left(7^{\text {th }} \mathrm{ed}\right.$.). Guilford publications.

Jakhar, D., \& Kaur, I. (2020). Callous attitude toward doctors during COVID-19. Dermatologic Therapy. https://doi.org/10.1111/dth. 13885

Jha, S., Shah, S., Calderon, M. D., Soin, A., \& Manchikanti, L. (2020). The effect of COVID-19 on interventional pain management practices: A physician burnout survey. Pain Physician, 23, 271-282.

Kearney, B. Y., \& Fleischer, B. J. (1997). Development of an instrument to measure exercise of self-care agency. Resarch in Nursing Health, 2(1), 25-34. https://doi.org/10.1002/nur.4770020105

Kline, R. B. (2005). Principles and practices of structural equation modeling (3rd ed.). Guilford. 
Koffman, J., Gross, J., Etkind, S. N., \& Selman, L. (2020). Uncertainty and COVID-19: How are we to respond? Journal of the Royal Society of Medicine, 113(6), 211-216. https://doi.org/10.1177/ 0141076820930665

Larsen, E. M., Donaldson, K., \& Mohanty, A. (2020). Conspiratorial thinking during COVID-19: The roles of paranoia, delusionproneness, and intolerance to uncertainty. Conspiratorial Thinking During Covid-19, https://doi.org/10.31234/osf.io/mb65f

Levy, M. L., Cummings, J. L., Fairbanks, L. A., Masterman, D., Miller, B. L., Craig, A. H., et al. (1998). Apathy is not depression. The Journal of Neuropsychiatry and Clinical Neurosciences, 10(3), 314-319.

Lilleholt, L., Zettler, I., Betsch, C., \& Böhm, R. (2020). Correlates and outcomes of pandemic fatigue. 1-50. https://doi.org/10.31234/osf. io/2xvbr

Lin, C. Y., Broström, A., Griffiths, M. D., \& Pakpour, A. H. (2020). Investigating mediated effects of fear of COVID-19 and COVID19 misunderstanding in the association between problematic social media use, psychological distress, and insomnia. Internet Interventions, 21. https://doi.org/10.1016/j.invent.2020.100345

Little, T. D., Rhemtulla, M., Gibson, K., \& Schoemann, A. M. (2013). Why items versus parcels controversy needn't be one. Psychological Methods, 18, 285-300.

Malach-Pines, A. (2005). The Burnout Measure Short version. International Journal of Stress Management, 12(1), 78-88. https://doi. org/10.1037/1072-5245.12.1.78

Mak, W. W., Law, R. W., Woo, J., Cheung, F. M., \& Lee, D. (2009). Social support and psychological adjustment to SARS: The mediating role of self-care self-efficacy. Psychology and Health, 24(2), 161-174. https://doi.org/10.1080/08870440701447649

Mamun, M. A., \& Griffiths, M. D. (2020). First COVID-19 suicide case in Bangladesh due to fear of COVID-19 and xenophobia: Possible suicide prevention strategies. Asian Journal of Psychiatry, 51. https://doi.org/10.1016/j.ajp.2020.102073

Marcus, J. (2020). Quarantine fatigue is real. The Atlantic. https:// www.theatlantic.com/ideas/archive/2020/05/quarantine-fatiguereal-and-shaming-people-wont-help/611482/

Marin, R. S. (1990). Differential diagnosis and classification of apathy. Am J Psychiatry, 147(1), 22-30.

Marin, R. S., Biedrzycki, R. C., \& Firinciogullari, S. (1991). Reliability and validity of the Apathy Evaluation Scale. Psychiatry Research, 38(2), 143-162. https://doi.org/10.1016/0165-1781(91)90040-V

Maslach, C., \& Leiter, M. P. (2016). Understanding the burnout experience: Recent research and its implications for psychiatry. World Psychiatry, 15(2), 103-111.

McKay, D., Minaya, C., \& Storch, E. A. (2020). Conducting exposure and response prevention treatment for contamination fears during COVID-19: The behavioral immune system impact on clinician approaches to treatment. Journal of Anxiety Disorders, 74, 1-4. https://doi.org/10.1016/j.janxdis.2020.102270

Mertens, G., Gerritsen, L., Duijndam, S., Salemink, E., \& Engelhard, I. M. (2020). Fear of the coronavirus (COVID-19): Predictors in an online study conducted in March 2020. Journal of Anxiety Disorders. https://doi.org/10.1016/j.janxdis.2020.102258

Michie, S., West, R., \& Harvey, N. (2020). The concept of "fatigue" in tackling Covid-19. BMJ, 371, m4171. https://doi.org/10.1136/ bmj.m4171

Moreno, C., Wykes, T., Galderisi, S., Nordentoft, M., Crossley, N., Jones, N., et al. (2020). How mental health care should change as a consequence of the COVID-19 pandemic. The Lancet Psychiatry, 7(9), 813-824. https://doi.org/10.1016/S2215-0366(20) 30307-2

Morgul, E., Bener, A., Atak, M., Akyel, S., Aktaş, S., Bhugra, D., Ventriglio, A., Jordan, T.R. (2020) COVID-19 pandemic and psychological fatigue in Turkey. International Journal of Social Psychiatry, 1-8. 10:20764020941889. doi: 10.1177/0020764020941889.
Murphy, J.F.A. (2020). Pandemic fatigue. Irish Medical Journal, 113(6), 1-3. https://www.lenus.ie/bitstream/handle/10147/627889/ Pandemic-Fatigue.pdf?sequence $=1$

Murthy, R. S. (2020). COVID-19 pandemic and emotional health: Social psychiatry perspective. Indian Journal of Social Psychiatry, 36(5), 24-42. https://doi.org/10.4103/ijsp.ijsp_293_20

Nagasawa, S. (2020). Tolerance for uncertainty: A COVID-19 workbook: A guide to accept your feelings, tolerate distress, and thrive. Retrieved from https://hullservices.ca/wp-content/uploads/2020/ 04/Tolerance-for-Uncertainty-Workbook-2.pdf

Nahcivan, N. (1993). Sağlıklı gençlerde ‘öz-bakım gücü’ ve aile ortamının etkisi [The 'self-care power' and the impact of family environment in healthy young people]. Yayınlanmamış Doktora Tezi [Unpublished Doctoral Dissertation], Sağlık Bilimleri Enstitüsü [Health Sciences Institute], Istanbul Universitesi [Istanbul University], Istanbul, Turkey.

Nitschke, J.P., Forbes, P.A.G., Ali, N., Cutler, J., Apps, M.A.J., Lockwood, P.L., Lamm, C. (2020). Resilience during uncertainty? Greater social connectedness during COVID-19 lockdown is associated with reduced distress and fatigue. British Journal of Health Psychology, 1-17. https://doi.org/10.1111/bjhp.12485

Ornell, F., Schuch, J. B., Sordi, A. O., \& Kessler, F. H. P. (2020). "Pandemic fear" and COVID-19: mental health burden and strategies. Brazilian Journal of Psychiatry, 42(3), 232-235. https://doi.org/ 10.1590/1516-4446-2020-0008

Padala, P. R., Desouza, C. V., Almeida, S., Shivaswamy, V., Ariyarathna, K., Rouse, L., Burke, W. J., \& Petty, F. (2008). The impact of apathy on glycemic control in diabetes: A cross-sectional study. Diabetes Research and Clinical Practice, 79, 37-41. https://doi. org/10.1016/j.diabres.2007.06.012

Pakpour, A. H., \& Griffiths, M. D. (2020). The fear of COVID-19 and its role in preventive behaviors. Journal of Concurrent Disorders. ISSN 2562-7546. http://irep.ntu.ac.uk/id/eprint/39561/

Pakpour, A. H., Griffiths, M. D., \& Lin, C. Y. (2020). Assessing psychological response to the COVID-19: the fear of COVID19 Scale and the COVID Stress Scales. International Journal of Mental Health and Addiction. https://doi.org/10.1007/ s11469-020-00334-9

Park, S. C., \& Park, Y. C. (2020). Mental health care measures in response to the 2019 novel coronavirus outbreak in Korea. Psychiatry Investigation, 17(2), 85-86. doi: 10.30773/pi.2020.0058

Parlapani, E., Holeva, V., Nikopoulou, V. A., Sereslis, K., Athanasiadou, M., Godosidis, A., et al. (2020). Intolerance of uncertainty and loneliness in older adults during the COVID-19 pandemic. Frontiers in Psychiatry, 11. https://doi.org/10.3389/fpsyt.2020. 00842

Person, B., Sy, F., Holton, K., Govert, B., \& Liang, A. (2004). Fear and stigma: The epidemic within the SARS outbreak. Emerging Infectious Diseases, 10(2), 358. https://doi.org/10.3201/eid1002. 030750

Peteet, J. R. (2020). COVID-19 Anxiety. Journal of Religion and Health, 1-2. https://doi.org/10.1007/s10943-020-01041-4

Queen, D., \& Harding, K. (2020). Societal pandemic burnout: A COVID legacy. International Wound Journal, 17(4). https://doi. org/10.1111/iwj.13441

Rettie, H., \& Daniels, J. (2020). Coping and tolerance of uncertainty: Predictors and mediators of mental health during the COVID19 pandemic. American Psychologist. http://doi.org/10.1037/ amp0000710

Reznik, A., Gritsenko, V., Konstantinov, V., Khamenka, N., \& Isralowitz, R. (2020). COVID-19 fear in Eastern Europe: Validation of the Fear of COVID-19 Scale. International Journal of Mental Health and Addiction. https://doi.org/10.1007/s11469-020-00283-3

Rocha, C. M., \& Chelladurai, P. (2012). Item parcels in structural equation modeling: An applied study in sport management. 
International Journal of Psychology and Behavioral Sciences, 2(1), 46-53. https://doi.org/10.5923/j.ijpbs.20120201.07

Rossell, S. L., Neill, E., Phillipou, A., Tan, E. J., Toh, W. L., Rheenen, T. E. V., \& Meyer, D. (2021). An overview of current mental health in the general population of Australia during the COVID19 pandemic: Results from the COLLATE project, Psychiatry Research, 296, 113660, https://doi.org/10.1016/j.psychres.2020. 113660.

Sarıçam, H., Deveci, M., \& Ahmetoğlu, E. (2020). The examination of hope, intolerance of uncertainty and resilience levels in parents having disabled children. Global Journal of Psychology Research: New Trends and Issues, 10(1), 118-131.https://doi.org/10.18844/ gjpr.v10i1.4398

Satici, B., Saricali, M., Satici, S. A., \& Griffiths, M. D. (2020). Intolerance of uncertainty and mental wellbeing: Serial mediation by rumination and fear of COVID-19. International Journal of Mental Health and Addiction. https://doi.org/10.1007/ s11469-020-00305-0

Sasangohar, F., Jones, S. L., Masud, F. N., Vahidy, F. S., \& Kash, B. A. (2020). Provider burnout and fatigue during the COVID19 pandemic: lessons learned from a high-volume intensive care unit. Anesthesia and Analgesia. 1-6. https://doi.org/10.1213/ANE. 0000000000004866

Schumacker, R. E., \& Lomax, R. G. (2010). A beginner's guide to structural equation modeling (3rd ed.). Routledge.

Shigemura, J., Ursano, R. J., Morganstein, J. C., Kurosawa, M., \& Benedek, D. M. (2020). Public responses to the novel 2019 coronavirus (2019-nCoV) in Japan: Mental health consequences and target populations. Psychiatry and Clinical Neurosciences, 74(4), 281-282. https://doi.org/10.1111/pcn.12988

Skorvanek, M., Rosenberger, J., Gdovinova, Z., Nagyova, I., Saeedian, R. G., Groothoff, J. W., \& Dijk, J. P. (2013). Apathy in elderly nondemented patients with Parkinson's disease: clinical determinants and relationship to quality of life. Journal of Geriatric Psychiatry and Neurology, 26(4), 237-243. https://doi.org/10.1177/ 0891988713500587

Soraci, P., Ferrari, A., Abbiati, F. A., Del Fante, E., De Pace, R., Urso, A., \& Griffiths, M. D. (2020). Validation and psychometric evaluation of the Italian version of the Fear of COVID-19 Scale. International Journal of Mental Health and Addiction, 1-10. https:// doi.org/10.1007/s11469-020-00277-1

Sultanov, S., Khodzhaeva, N., Ashurov, Z., Lyan, Y., \& Shadmanova, L. (2020). Features of minor depressive disorder subtypes in conditions of COVID-19 pandemic. Indian Journal of Psychiatry, 62(9), 476-478. Available from: https://www.indianjpsychiatry. org/text.asp?2020/62/9/476/296518

Tanhan, A. (2020). Utilizing online photovoice (OPV) methodology to address biopsychosocial spiritual economic issues and wellbeing during COVID-19: Adapting OPV to Turkish. Turkish Studies, 15(4), 1029-1086. https://doi.org/10.7827/TurkishStudies.44451

Tanhan, A., Yavuz, K. F., Young, J. S., Nalbant, A., Arslan, G., Yıldırım, M., Ulusoy, S., Genç, E., Uğur, E., \& Çiçek, İ. (2020). A proposed framework based on literature review of online contextual mental health services to enhance wellbeing and address psychopathology during COVID-19. Electronic Journal of General Medicine, 17(6), em254. https://doi.org/10.29333/ejgm/8316

Teng, Z., Wei, Z., Qiu, Y., Tan, Y., Chen, J., Tang, H., et al. (2020). Psychological status and fatigue of frontline staff two months after the COVID-19 pandemic outbreak in China: A cross-sectional study. Journal of Affective Disorders, 275, 247-252. https://doi. org/10.1016/j.jad.2020.06.032

Van Reekum, R., Stuss, D. T., \& Ostrander, L. (2005). Apathy: Why care? The Journal of Neuropsychiatry and Clinical Neurosciences, 17(1), 7-19.

Vindegaard, N., \& Benros, M. E. (2020). COVID-19 pandemic and mental health consequences: Systematic review of the current evidence. Brain Behavior, and Immunity, 89, 531-542. https:// doi.org/10.1016/j.bbi.2020.05.048

Voitsidis, P., Gliatas, I., Bairachtari, V., Papadopoulou, K., Papageorgiou, G., Parlapani, E., et al. (2020). Insomnia during the COVID19 pandemic in a Greek population. Psychiatry Research, 289, 1-2. https://doi.org/10.1016/j.psychres.2020.113076

Williams, L. J., Vandenberg, R. J., \& Edwards, J. R. (2009). 12 structural equation modeling in management research: A guide for improved analysis. The Academy of Management Annals, 3(1), 543-604. https://doi.org/10.1080/19416520903065683

Witteveen, D., \& Velthorst, E. (2020). Economic hardship and mental health complaints during COVID-19. Proceedings of the National Academy of Sciences of the United States of America, 117(44), 27277-27284. https://doi.org/10.1073/pnas.2009609117

World Health Organization. (2009). Self-care in the context of primary health care (No. SEA-HSD-320). WHO Regional Office for South-East Asia.

World Health Organisation (2020). WHO Coronavirus Disease (COVID-19) Dashboard https://covid19.who.int/

World Health Organization (2020). Pandemic fatigue -Reinvigorating the public to prevent COVID-19. https://apps.who.int/iris/bitst ream/handle/10665/335820/WHO-EURO-2020-1160-4090655390-eng.pdf

Xiang, Y. T., Yang, Y., Li, W., Zhang, L., Zhang, Q., Cheung, T., \& $\mathrm{Ng}$, C. H. (2020). Timely mental health care for the 2019 novel Coronavirus outbreak is urgently needed. The Lancet Psychiatry, 7(3), 228-229. https://doi.org/10.1016/S2215-0366(20)30046-8

Yalçın, İ., Can, N., Mançe Çalışır, Ö., Yalçın, S., \& Çolak, B. (2021). Latent profile analysis of COVID-19 fear, depression, anxiety, stress, mindfulness, and resilience. Current Psychology, 1-11. https://doi.org/10.1007/s12144-021-01667-x

Yildırım, M., \& Solmaz, F. (2020). COVID-19 burnout, COVID-19 stress and resilience: Initial psychometric properties of COVID-19 burnout scale. Death Studies, 1-9. https://doi.org/10.1080/07481 187.2020.1818885

Zerbe, K. J. (2020). Pandemic Fatigue: Facing the Body's Inexorable Demands in the Time of COVID-19. Journal of the American Psychoanalytic Association, 68(3), 475-478. https://doi.org/10. 1177/0003065120938774

Zou, S., Liu, Z. H., Yan, X., Wang, H., Li, Y., Xu, X., Du, X., Zhang, L., Zhang, Q., Jackson, T., Ungvari, G. S., \& Xiang, Y. T. (2020). Prevalence and correlates of fatigue and its association with quality of life among clinically stable older psychiatric patients during the COVID-19 outbreak: a cross-sectional study. Globalization and Health, 16(1), 1-7. https://doi.org/10.1186/ s12992-020-00644-6

Publisher's note Springer Nature remains neutral with regard to jurisdictional claims in published maps and institutional affiliations. 